\title{
Allergic Rhinitis in Children - New Therapeutic Options
}

\author{
Janeczek $\mathrm{K}^{*}$ and Emeryk A \\ The Department of Children's Lung Diseases and Rheumatology, Poland \\ *Corresponding author: The Department of Children's Lung Diseases and Rheumatology, Poland
}

\begin{tabular}{|c|c|}
\hline ARTICLE INFO & ABSTRACT \\
\hline Received: 㓞 February 13, 2019 & Abbreviations: AR: Allergic Rhinitis; PBL: Polyvalent Bacterial Lysates; RQLQ \\
\hline Published: 慧 February 21, 2019 & $\begin{array}{l}\text { Quality of Life; QOL: Quality of Live; MRQLQ: Mini Rhinoconjunctivitis Quality of Life } \\
\text { Questionnaire; LP: Lactobacillus Paracasei }\end{array}$ \\
\hline
\end{tabular}

Citation: Janeczek K, Emeryk A. Allergic Rhinitis in Children - New Therapeutic Options. Biomed J Sci \& Tech Res 14(5)-2019. BJSTR. MS.ID.002623.

\section{Introduction}

Allergic rhinitis (AR) is an inflammatory process of the nasal mucosa, most often IgE dependent, caused by environmental allergens. Typical symptoms of the disease are: an aqueous secretion from the nose, nasal congestion, itching of the nose and sneezing, which disappear spontaneously or under the influence of treatment. AR is the most common allergic disease in the world, affecting $5-40 \%$ of the pediatric population [1]. Due to the time of exposure to the agent causing allergic rhinitis, it can be divided into seasonal (SAR) and perennial (PAR). Currently, there are four ways of dealing with patients with AR: education of patients and their parents, eliminating allergens, pharmacotherapy (nasal glucocorticoids, nasal and oral antihistamines, alpha-mimetics, anticholinergics, anti-leukotrienes, cromones, anti-IgE therapy), and allergen immunotherapy (subcutaneous and sublingual) [1-3]. Due to the high incidence of AR, the negative impact of the disease on the quality of life, and incomplete effectiveness of previously available therapeutic methods, new methods of treatment are being developed [4]. Literature sources and the authors' own experiences indicate the possibility of using bacterial lysates, probiotics and vitamin D in AR therapy for children.

\section{Polyvalent Bacterial Lysates (PBL)}

Polyvalent bacterial lysates (PBL) are a mixture of antigens obtained from inactivated bacteria which are the most common etiologic agents of infections of the respiratory system. PBL have been used for many years to prevent respiratory infections in children and adults. In addition, they shorten the duration of respiratory infections and reduce the frequency of antibiotic therapy. We can divide PBL according to the method of obtaining them into chemical (PCBL) and mechanical lysates (PMBL). It is postulated that mechanical lysates show a higher immunogenic potential compared to chemical lysates [5]. Recent research highlights the immunoregulatory potential of PBL, indicating the possibility of their future use in the prevention and treatment of other diseases, including atopic dermatitis, AR, and asthma [613]. In Banche, we find evidence of the effectiveness of bacterial lysates in SAR therapy. The authors of the study found a clinically significant improvement in the severity of SAR symptoms in $61.5 \%$ of patients receiving PMBL, while in the remaining patients of this group (38.5\%) they did not observe improvement or worsening of the disease vs. the placebo group, in which SAR deterioration occurred in $53.4 \%$ of subjects [9].

In the 2017 grass pollen season, the authors of this article conducted a randomized, open-label study, assessing the effect of PMBL on the clinical course of SAR. The study was performed on a group of 38 children aged 5-17 years suffering from SAR caused by grass pollen. Patients were randomly divided into two groups. One group received additional PMBL during the grass pollen season, and the remaining patients used only standard AR therapy. In patients treated with additional PMBL, the severity of SAR decreased vs. the group not taking PMBL in the second half of the grass pollen season [14]. The obtained results prompted the authors to re-conduct the study in the following season of grass pollination (2018). This was a multi-centre, prospective randomized, double-blind, placebo- 
controlled study in parallel groups (PMBL vs. placebo), whose strongly positive results will be presented at the EAACI 2019 congress in Lisbon.

\section{Probiotics}

A lot of experimental and clinical data points to the possible benefits of probiotics in the pollen season in children and adults with AR. The results of research in this area carried out up to 2015 were summarized by Zajac et al. [15] and Güvenç et al. [16] in their meta-analyses. The first meta-analysis included 23 studies with 1919 adult and pediatric patients with SAR or PAR treated with 3 weeks to 12 months with probiotic or placebo. Seventeen studies showed a significant clinical benefit from the use of probiotics in at least one outcome measure when compared to placebo, while 6 trials showed no benefit. Meta-analysis demonstrated significant improvement in Rhinitis Quality of Life (RQLQ) global scores compared to placebo (SMD -2.23, $\mathrm{p}=0.02$ ) and RQLQ nasal symptom score (SMD -1.21, $\mathrm{p}<0.00001$ ), but no effect was found for Rhinitis Total Symptom Scores, total IgE or allergen-specific IgE levels. To the second meta-analyses 22 randomized, double-blind, placebo-controlled studies were included with 2242 patients aged 2 to 65 years with SAR or PAR. Patients received daily probiotic or placebo for 4 weeks to 12 months as an adjuvant to standard allergy therapies. Seventeen trials showed significant benefit of probiotics clinically, whereas eight trials showed significant improvement in immunologic parameters compared with placebo. All five studies with Lactobacillus paracasei (LP) strains demonstrated clinically significant improvements compared with placebo. Probiotics showed significant reduction in nasal and ocular symptoms score (SMD -1.23, p<0.001; and -1.84, p<0.001; respectively), total, nasal, and ocular Quality of Live (QoL) scores compared with placebo (SMD -1.84, $\mathrm{p}<0.001$; SMD -2.30, $\mathrm{p}=0.006$; and SMD -3.11, $\mathrm{p}=0.005$; respectively). Although heterogeneity was high, in subgroup analysis, SMD for total, nasal and ocular symptoms with patients with SAR and for nasal QoL scores for studies with LP-33 strain were significant and homogenous. Scores of nasal blockage, rhinorrhea, and nasal itching were significantly lower in the probiotic group compared with placebo. The T-helper 1 to T-helper 2 ratio was significantly lower in the probiotic group compared with placebo (SMD -0.78, p=0.045).

Miraglia Del Giudise et al. showed that children with SAR treated with probiotic mixture (Bifidobacterium mixture: B. longum BB536, B. infantis M-63, B. breve M-16V) achieved a significant improvement of symptoms ( $\mathrm{p}<0.005)$, and QoL $(\mathrm{p}<0.001)$. Placebo group had worsening of symptoms $(\mathrm{p}<0.005)$ and QoL $(\mathrm{p}<0.001)$. The use of rescue medications was overlapping in the two groups. The intergroup analysis showed that probiotic mixture was significantly superior than placebo for all assessed parameters [17].

Dennis-Wall et al. evaluated the effectiveness of probiotics in adults with AR. The authors of this study reported an improvement in Mini Rhinoconjunctivitis Quality of Life Questionnaire (MRQLQ) global score from baseline to pollen peak $(-0.68 \pm 0.13)$ when compared with the placebo group $(-0.19 \pm 0.14 ; \mathrm{P}=0.0092)$. Both serum total IgE and the percentage of Tregs increased from baseline to week 6 , but changes were not different between groups [18].

Probiotics have been posited to elicit immunomodulatory effects on atopic disease like AR via gut-associated lymphoid tissue. Stimulation of dendritic cells induces Th1 responses via IL-12 and IFN- $\gamma$, upregulation of Treg cells via IL-10 and TGF- $\beta$, and suppression of Th2 pathways through downregulation of IL-4, sIgE, IgG1, and IgA [19-20]. Additional randomized controlled trials using specific probiotic strains and consistent outcome measures are urgent needed to confirm this putative efficacy and allow for evidence-based recommendations.

\section{Vitamin D3}

The third option may be complementary AR therapy with the use of vitamin D3. Apart from its effect on calcium-phosphate homeostasis, this vitamin also participates in the regulation of the primary and secondary immune response. The effect of vitamin D on immune system cells has been demonstrated, including dendritic cells, macrophages, $\mathrm{T}$ and B lymphocytes, NK cells, eosinophils and neutrophils. Vitamin D also regulates the production of various cytokines and the expression of transcription factors [21]. Vitamin D deficiency is considered as an important element in the pathogenesis of various allergic diseases [22]. Therefore, in recent years, numerous attempts have been made to assess the contribution of this vitamin to the pathophysiology of these diseases. Both experimental and clinical studies show that vitamin $\mathrm{D}$ is connected with $\mathrm{AR}$, but these results are not consistent and sometimes even contradictory.

A meta-analysis of 19 clinical trials from 2016 showed that lower levels of vitamin D3 were associated with a higher incidence of AR in children, which was not demonstrated in adults [23]. Polish researchers conducted an attempt to treat with vitamin D3 in children with SAR who were allergic to grass pollen [25]. The applied dose of vitamin D3 (1000 IU per day, during the entire grass pollen season) statistically significantly reduced nasal symptoms of the disease, decreased the consumption of anti-allergic drugs, and also improved the function of the lungs. Another recently published study demonstrated the antiallergic effect of intranasal 1,25-dihydroxyvitamin D3 in an allergic rhinitis mouse model [25]. On the other hand, evidence from clinical studies conducted by HuiQin shows a slight tendency that the serum vitamin D level might be inversely associated with the risk of AR[26]. Additional studies are needed to better understand how vitamin D influences AR.

\section{Summary}

The therapeutic methods presented in this article may enable better control of AR in children. These methods are relatively cheap and easy to quickly introduce into clinical practice. 


\section{References}

1. Bousquet J, Khaltaev N, Cruz AA, Denburg J, Fokkens WJ, et al. (2008) Allergic Rhinitis and its Impact on Asthma (ARIA) 2008 update (in collaboration with the World Health Organization, GA2LEN and AllerGen). Allergy 63(supl. 86): 8-160.

2. Brożek JL, Bousquet J, Baena Cagnani CE, Bonini S, Canonica GW, et al. (2010) Allergic Rhinitis and its Impact on Asthma (ARIA) guidelines: 2010 revision. J Allergy Clin Immunol 126(3): 466-476.

3. Brożek JL, Bousquet J, Agache I, Agarwal A, Bachert C, et al. (2017) Allergic Rhinitis and its Impact on Asthma (ARIA) guidelines - 2016 revision. J Allergy Clin Immunol 140(4): 950-958.

4. Heffler E, Brussino L, Del Giacco S, Paoletti G, Minciullo PL, et al. (2019) New drugs in early-stage clinical trials for allergic rhinitis. Expert Opin Investig Drugs 28(3): 267-273.

5. Macchi A, Vecchia LD (2005) Open comparative, randomized controlled clinical study of a new immunostimulating bacterial lysate in the prophylaxis of upper respiratory tract infections. Arzneim Forsch Drug Res 55(5): 276-281.

6. Bodemer C, Guillet G, Cambazard F, Boralevi F, Ballarini S, et al. (2017) Adjuvant treatment with the bacterial lysate (OM-85) improves management of atopic dermatitis: a randomized study. PLoS One 12(3): e0161555.

7. Lau S, Gerhold K, Zimmermann K, Ockeloen CW, Rossberg S, et al. (2012) Oral application of bacterial lysate in infancy decreases the risk of atopic dermatitis in children with 1 atopic parent in a randomized, placebocontrolled trial. J Allergy Clin Immunol 129(4): 1040-1047.

8. Razi CH, Harmancı K, Abacı A, Özdemir O, Hizli S, et al. (2010) The immunostimulant OM-85 BV prevents wheezing attacks in preschool children. J Allergy Clin Immunol 126(4): 763769.

9. Banche G, Allizond V, Mandras N, Garzaro M, Cavallo GP, et al. (2007) Improvement of clinical response in allergic rhinitis patients treated with an oral immunostimulating bacterial lysate: in vivo immunological effects. Int J Immunopathol Pharmacol 20(1): 129-138.

10. Edwards MR, Walton RP, Jackson DJ, Feleszko W, Skevaki C, et al. (2018) The potential of anti-infectives and immunomodulators as therapies for asthma and asthma exacerbations. Allergy 73(1): 50-63.

11. Navarro S, Cossalter G, Chiavaroli C, Kanda A, Fleury S, et al. (2011) The oral administration of bacterial extracts prevents asthma via the recruitment of regulatory T cells to the airways. Mucosal Immunol 4(1): 53-65.

12. Kearney SC, Dziekiewicz M, Feleszko W (2015) Immunoregulatory and immunostimulatory responses of bacterial lysates in respiratory infections and asthma. Ann Allergy Asthma Immunol 114(5): 364-369.

13. Liao J, Zhang $T$ (2014) Influence of OM-85 BV on hBD-1 and immunoglobulin in children with asthma and recurrent respiratory tract infection. Zhongguo Dang Dai Er Ke Za Zhi 16(5): 508-512.

\section{ISSN: 2574-1241}

DOI: 10.26717/BJSTR.2019.14.002623

Janeczek K. Biomed J Sci \& Tech Res

(C) This work is licensed under Creative

Commons Attribution 4.0 License

Submission Link: https://biomedres.us/submit-manuscript.php
14. Janeczek K, Emeryk A (2018) Effect of polyvalent bacterial lysate on the clinical course of pollen allergic rhinitis in children. Allergy 73: 354.

15. Zajac AE, Adams AS, Turner JH (2015) A systematic review and metaanalysis of probiotics for the treatment of allergic rhinitis. Int Forum Allergy Rhinol 5(6): 524-532.

16. Güvenç IA, Muluk NB, Mutlu FŞ, Eșki E, Altıntoprak N, et al. (2016) Do probiotics have a role in the treatment of allergic rhinitis? A comprehensive systematic review and meta-analysis. Am J Rhinol Allergy 30(5): 157-175.

17. Miraglia Del Giudice M, Indolfi C, Capasso M, Maiello N, Decimo F, et al. (2017) Bifidobacterium mixture (B longum BB536, B infantis M-63, B breve $\mathrm{M}-16 \mathrm{~V}$ ) treatment in children with seasonal allergic rhinitis and intermittent asthma. Ital J Pediatr 43(1): 25.

18. Dennis Wall JC, Culpepper T, Nieves C, Rowe CC, Burns AM, et al. (2017) Probiotics (Lactobacillus gasseri KS-13, Bifidobacterium bifidum G91 , and Bifidobacterium longum $\mathrm{MM}-2$ ) improve rhinoconjunctivitisspecific quality of life in individuals with seasonal allergies: a doubleblind, placebo-controlled, randomized trial. Am J Clin Nutr 105(3): 758-767.

19. Kim WG, Kang GD, Kim HI, Han MJ, Kim DH, et al. (2019) Bifidobacterium longum IM55 and Lactobacillus plantarum IM76 alleviate allergic rhinitis in mice by restoring Th2/Treg imbalance and gut microbiota disturbance. Benef Microbes 10(1): 55-67.

20. Plaza Diaz J, Ruiz Ojeda FJ, Gil Campos M, Gil A (2019) Mechanisms of Action of Probiotics. Adv Nutr 10(suppl.1): 49-66.

21. Di Rosa M, Malaguarnera M, Nicoletti F, Malaguarnera L (2011) Vitamin D3: a helpful immuno-modulator. Immunology 134(2): 123-139.

22. Akbar NA, Zacharek MA (2011) Vitamin D: immunomodulation of asthma, allergic rhinitis, and chronic rhinosinusitis. Curr Opin Otolaryngol Head Neck Surg 19(3): 224-228.

23. Kim YH, Kim KW, Kim MJ, Sol IS, Yoon SH, et al. (2016) Vitamin D levels in allergic rhinitis: a systematic review and meta-analysis. Pediatr Allergy Immunol 27(6): 580-590.

24. Jerzyńska J, Stelmach W, Rychlik B, Paweł Majak, Daniela Podlecka, et al. (2018) Clinical and immunological effects of vitamin D supplementation during the pollen season in children with allergic rhinitis. Arch Med Sci 14(1): 122-131.

25. Cho SW, Zhang YL, Ko YK, Shin JM, Lee JH, et al. (2019) Intranasal treatment with 1,25-dihydroxyvitamin D3 alleviates allergic rhinitis symptoms in a mouse model. Allergy Asthma Immunol Res 11(2): $267-$ 279.

26. Hui Qin T, Cheng L (2017) The role of vitamin D in allergic rhinitis. Asia Pac Allergy 7(2): 65-73.

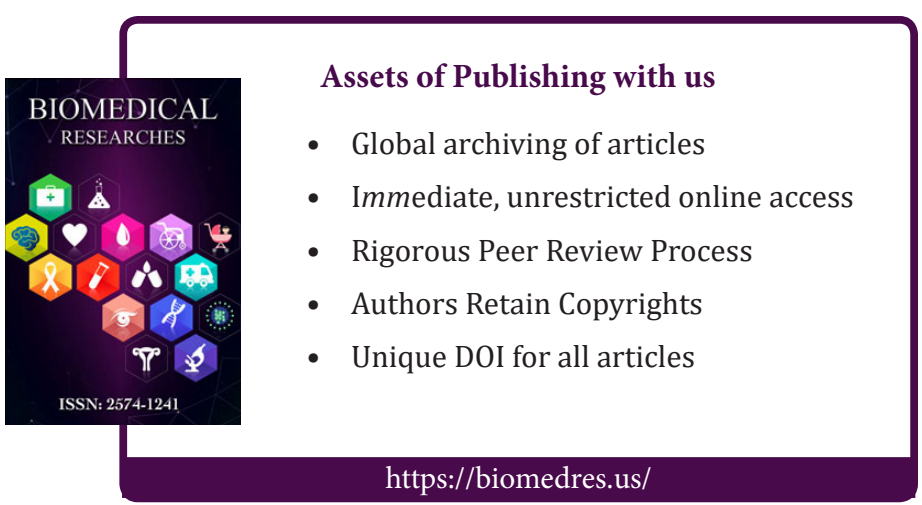

